Т. В. Каштелян

Белорусский государственный технологический университет

\title{
ЗНАЧЕНИЕ, ФАКТОРЫ И ПУТИ ИННОВАЦИОННОГО РАЗВИТИЯ ЛЕСНОЙ БИОЭКОНОМИКИ БЕЛАРУСИ В СОЦИОЛОГИЧЕСКОМ АСПЕКТЕ
}

В современных условиях глобальной конкуренции и многоаспектного пандемического кризиса актуализируется проблема достижения устойчивого экономического роста хозяйственных систем. Важную роль в ее решении играет биоэкономика, выступающая в качестве важнейшей системы жизнеобеспечения на базе биологических ресурсов. Лесная биоэкономика призвана создавать условия для устойчивого возобновления биоресурсов и их преобразования на базе имеющейся пространственной среды через задействование институциональных, инновационных, производственных и других факторов социально-экономического развития.

Целью работы является социологическое исследование лесной биоэкономики Беларуси и выявление на этой основе факторов агентного моделирования экономических отношений и в целом системного развития под влиянием имеющихся социокультурных поведенческих паттернов.

Метод исследования - анкетный опрос специалистов разных отраслей экономики. В этой связи нами были выделены две группы опрашиваемых работников: первая группа, которая обладает знаниями и умениями в области лесных и лесоинженерных технологий; вторая группа, в которой осуществляется подготовка по технологиям химической промышленности, промышленности стройматериалов и др.

Результатом исследований является социологический анализ сложившейся институциональной среды лесной биоэкономики. В статье представлены рейтинговые итоги ранжирования экологических проблем, решаемых, в частности, лесным сектором. Они сводятся к преимущественной реализации лесами водоохранной функции и к более выраженной климатической ориентированности.

Рейтинговые оценки для продуктовых позиций лесного сектора показали, что стратегические цели современного экономического развития основываются на приоритетности строительных материалов. Однако рациональные решения для инновационного развития и стратегического менеджмента должны аккумулировать задачи будущего, включающие системы креативного экопотребления.

Ключевые слова: биоэкономика, лесной сектор, респонденты, принципы лесопользования, технологии, инновационное развитие, нерыночные услуги лесов, гидрологическая функция лесов, стратегический менеджмент.

Для цитирования: Каштелян Т. В. Значение, факторы и пути инновационного развития лесной биоэкономики Беларуси в социологическом аспекте // Труды БГТУ. Сер. 5, Экономика и управление. 2021. № 2 (250). С. 83-88.

\author{
T. V. Kashtelyan \\ Belarusian State Technological University
}

\section{SIGNIFICANCE, FACTORS AND WAYS OF INNOVATIVE DEVELOPMENT OF THE FOREST BIOECONOMY OF BELARUS IN SOCIOLOGICAL ASPECT}

In the modern conditions of global competition and a multidimensional pandemic crisis, the problem of achieving sustainable economic growth of economic systems is being actualized. Bioeconomy plays an important role in its solution, acting as the most important life support system based on biological resources. Bioeconomy is designed to create conditions for the sustainable renewal of biological resources and their transformation on the basis of the existing spatial environment through the involvement of institutional, innovative, industrial and other factors of socio-economic development.

The aim of the work is a sociological study of the forest bioeconomy of Belarus and the identification on this basis of factors of agent modeling of economic relations and, in general, system development under the influence of existing socio-cultural behavioral patterns.

The research method is a questionnaire survey of specialists from different sectors of the economy. In this regard, we have identified two groups of interviewed employees: the first group, which has knowledge and skills in the field of forest and forest engineering technologies; the second group, which provides training in the technologies of the chemical industry, the building materials industry, etc.

The result of the research is a sociological analysis of the existing institutional environment of forest bioeconomy. The article presents the rating results of the ranking of environmental problems solved, in particular, in the forest sectors. They are reduced to the pre-property realization of the water protection function by forests and to a more pronounced climatic orientation. 
Rating assessments for the product positions of the forest sector have shown that the strategic goals of modern economic development are based on the priority of construction materials. However, rational solutions for innovative development and strategic management should accumulate the tasks of the future, including systems of creative eco-consumption.

Key words: bioeconomy, forest sector, respondents, principles of forest management, technologies, innovative development, non-market services of forests, hydrological function of forests, strategic management.

For citation: Kashtelyan T. V. Significance, factors and ways of innovative development of the forest bioeconomy of Belarus in sociological aspect. Proceedings of BSTU, issue 5, Economics and Management, 2021, no. 2 (250), pp. 83-88 (In Russian).

Введение. Биоэкономику определяют как экономическую деятельность, опирающуюся на устойчивое и инновационное (с помощью знаний) производство биомассы, обеспечивающей производство энергии, продовольствия, экологических и других услуг. Возможности биоэкономического развития Беларуси во многом определяются возобновляемыми ресурсами АПК и лесного сектора. При этом следует придерживаться двухкомпонентной цели. Первая компонента - это обеспечение здорового питания, а вторая - это экономика биологических ресурсов, которые представляют собой средства социально-экологической и экономической выгоды. Благодаря лесным ресурсам, распределенным по территории нашей страны, мы имеем как занятость определенной части населения, так и систему разнообразных источников доходов и развития.

Наше исследование посвящено социологическому анализу состояния лесной биоэкономики. Оно проводилось по двум группам респондентов, которые были разделены на тех, чьи профессиональные интересы и текущая деятельность, а также получаемые знания, умения, навыки связаны с лесом как объектом биоэкономики, и на тех, которые не являются представителями лесного сектора и не включены в систему организации учебного процесса по лесным и лесоинженерным технологиям.

Основная часть. Биоэкономическое развитие концептуально базируется на ресурсной теории [1], оно предполагает анализ местных стратегий $[2,3\rceil$ социально-экономического развития и реализацию различных проектов. В Беларуси применяется система внешних оценок состояния лесов и деятельности природопользователей в целом. Лес рассматривается как инструмент для улучшения экологической обстановки, как источник средств к существованию для населения сельских и городских территорий. Основываясь на программах развития лесного хозяйства, решаются проблемы обезлесения страны. К сожалению, пока не идет речи о получении институционально закрепленных возможностей и реальных выгод от накопления углерода в лесах. В то же время повышение эффективности управления лесами в качестве фактора биоэкономического развития Беларуси активно изучается.

В социологическом анализе, как описывает Б. Зигмунт [1], важен момент передачи информации «с низших ступеней иерархической лестницы на высшие, становясь все более объемной и обобщающей». На этом базируется обратная связь управления любым социальным объектом. Лесная биоэкономика в этом отношении не является исключением. Приверженность к планированию национальных правил поведения в лесах Беларуси, квот и механизмов для контроля за состоянием территорий, контроля добычи дикой флоры и фауны не исключает, а, наоборот, предполагает изучение гражданских позиций для поддержки рационализации путей лесного биоэкономического развития.

Потенциал лесного сектора в ближайшей и отдаленной перспективах эколого-экономической безопасности нашей страны нельзя недооценивать. При этом, имея в виду большое разнообразие термина «лес», в своем исследовании мы представили его в качестве интегрированной экосистемы, состоящей из биологических ресурсов с доминированием определенных пород деревьев. В практической деятельности субъектов хозяйствования Беларуси на законодательном уровне мы имеем дело с лесными площадями, различными иерархическими уровнями, стратегиями и тактиками координации, системами мониторинга и институтами собственности. Но чтобы собрать и проиллюстрировать значение лесной биоэкономики для представителей различных организаций, в анкетах мы использовали вопросы, не связанные с проблемой владения землей и ресурсами, а так называемые «потоковые» подходы социологического опроса, связанные с экологической обстановкой, рыночными и финансовыми аспектами потребления.

Лесная биоэкономика - организация, находящаяся в интегрированных естественных условиях нашей страны. В экологическом контексте лесная биоэкономика предоставляет открытое пространство для жизнедеятельности населения. А с позиций экономической деятельности в этом открытом пространстве осуществляется лесопользование, которое выступает в качестве основы формирования финансовых ресурсов. Важными 
составляющими при этом являются системы обмена стоимостью, прав собственности, политика рыночной адаптации, трансфертов, совместной деятельности, раздела продукции и др.

Поведенческие особенности анкетируемых работников можно характеризовать как «креативные», так как это молодые люди в возрасте до 30 лет, преимущественно мужчины. Наши исследования были направлены на выявление характера экономического поведения в условиях ресурсно-экологической трансформации на пути к инновациям в области управления маркетингом, услугами лесных экосистем и финансами.

Проблема белорусской практики лесопользования заключается в значительном числе нормативно-правовых актов, регулирующих экономические отношения как внутри лесного сектора (правила реализации древесины и др.), так и относящихся к публичному праву, - гражданских, антимонопольных, налоговых прав и др. Характерной особенностью современной лесной биоэкономики нашей страны являются рамки проектного государственного финансирования осуществляемых работ в отрасли лесного хозяйства. Для развития указанной отрасли экономики требуются немалые средства. Координацию этого направления работы осуществляет Министерство лесного хозяйства. Очевидно, что экономическая стратегия отрасли должна быть обозначена не столько через изменения в регулировании данной структурой процессов планирования работ, сколько видением рыночных аспектов устойчивого развития территорий при их системном исследовании. Потенциал лесного биоэкономического развития можно интерпретировать через понятия достижения успеха в области устойчивости лесопользования.

Является ли Беларусь успешной в указанном отношении страной? На этот вопрос был получен не всегда однозначный ответ. Так, ответы респондентов, имеющих специализированное образование в области лесных и лесоинженерных технологий, только на 28,6\% были положительными. Казалось бы, что такой достаточно низкий уровень положительной оценки устойчивости лесопользования свидетельствует в первую очередь о проблемах в системе поставок древесного сырья. Но при этом хотелось бы обратить внимание на разброс мнений респондентов в зависимости от участия их в организационных структурах, относящихся и не относящихся к лесному сектору. Так, например, мастер цеха частного предприятия деревообработки отвечает положительно об устойчивости развития лесопользования, а мастер лесопункта в лесхозе, наоборот, отрицательно. Таким образом, можно заключить, что положительные ответы о реализации устойчивости могут быть связаны не столько с теоретическим недопониманием принципов непрерывного неистощительного постоянного лесопользования (ННПЛ), сколько с отсутствием четкого представления о финансовом состоянии дел в системе отраслей лесного сектора.

Данный опрос (по специалистам лесных отраслей) мы сравнили с мнениями тех респондентов, которые не изучали принципы ННПЛ. Интересно, что их ответы про устойчивость лесопользования также не выделялись высоким процентом охвата - 30,3\% от общего числа группы респондентов. В то же время надо отметить, и это естественно, что количество ответов «не знаю» превышало даже указанный 30\%-ный уровень от общего числи опрошенных. Приведенные данные позволяют сделать выводы о необходимости следования четким параметрам оценок устойчивости, которые бы мы могли интерпретировать в категориях «слабой» и «сильной» устойчивости для исследуемых отраслей экономики. Кроме того, не исключается и серьезная проблема взаимосоответствия целей и средств устойчивого развития лесопользования.

Гораздо более понятными для респондентов оказались вопросы о важности решения экологических проблем, на которые были даны ответы с применением метода ранжирования. Анкетируемые участники проблему обезлесения страны обозначают как насущную, весьма актуальную. Причем специалисты, не относящиеся к отраслям лесного комплекса, оценили проблему обезлесения как реальную угрозу на 68,5\% и утрату биоразнообразия - на 63,1\%. По сравнению с указанными респондентами для специалистов лесной отрасли проблема обезлесения представляет еще большую проблему (71\%), а вот вероятность исчезновения биоразнообразия оценена в более низкой степени - 60\%. Это свидетельствует о внимательном отношении белорусов к экологическим проблемам, причем независимо от того, в каких структурах они заняты, связаны они или нет с управлением лесами.

Отталкиваясь от оценки важности реализации стратегии устойчивого развития лесопользования, нами были сформулированы экологические проблемы для установления рангов, среди которых: изменение климата; загрязнение воды; утрата экосистем; уменьшение биоразнообразия и др. Ответы на вопросы среди анкетируемых со специальным лесотехническим образованием получились следующими. $36,7 \%$ опрошенных считают, что проблема изменения климата очевидная и важность ее решения заслуживает первого места среди других. А более 38\% участников опроса на первое место поставили проблему загрязнения воды. Понятно, что именно эта группа анкетируемых работников как никто другой является приверженной парадигме 
«зеленого» инвестирования. Во всяком случае только этим специалистам как никаким другим известно, как долго растут деревья для того, чтобы их получить в спелом виде, что для достижения этих целей требуются огромные затраты, а в институциональном аспекте продажи древесного сырья не соответствуют всем затратам лесного хозяйства.

Использование лесных ресурсов в биоэкономике предусматривает оценку экоэффективности. Критериями ее являются не только минимальные затраты, но и отсутствие противоречий экономических интересов субъектов хозяйствования. Лесные экосистемы во всем мире позиционируются как пространственные локации для сотрудничающих пользователей ресурсов и их потоков. Государство может использовать свои полномочия для пересмотра содержания прав собственности в соответствии с инициативами, соглашениями или для создания возможностей повышения социального благосостояния населения. Чтобы запустить процессы децентрализации финансирования устойчивого развития лесопользования в Беларуси, следует иметь не только согласованные права доступа к лесным ресурсам, но и широкомасштабную оценку воздействия лесов на уровень жизни местного населения и окружающую среду. Сфера нерыночных услуг лесных территорий является одной из создающих ценность для белорусского общества. Лесная биоэкономика призвана способствовать получению выгод от более эффективного предоставления экосистемных услуг.

Применяя метод начисления баллов за предпочтительные источники финансирования нерыночных услуг лесов (экосистемных), группа, относящаяся непосредственно к лесным отраслям, высказалась, в первую очередь, за госбюджетное финансирование. В то же время группа анкетируемых, которая не изучает возможности финансирования и реальные источники реформ лесного сектора, на первое место поставила самих пользователей нерыночных услуг, а на втоpoe - госбюджет. Таким образом, к белорусам приходит осознание того, что потребители нерыночных услуг лесов вполне могут следовать правилам платности природопользования.

Обратимся к теории потребительской и меновой стоимости. Стоимость - это концепция, цель которой объяснить главным образом меновую стоимость. Формируя меновую стоимость таким образом, чтобы покрывалась потребительская стоимость, можно создавать стимулы для роста экономики и инвестиционной привлекательности территорий. Позитивные тенденции непрерывного возрастания меновой стоимости - это конкретный рационалистически-инструментальный подход для создания и покрытия потребительских ценностей.
Налогово-бюджетные источники повышения эффективности биоэкономики - это важная дополнительная система создания стимулов. При их использовании необходимо анализировать и четко представлять воздействия определенных рычагов и методов на оздоровление компаний и повышение эффективности. Понятно, что главным постулатом функционирования государства как общественного института является принцип обмена налогов на услуги населению, предоставляемые государством. Но если роль государства как собственника ресурсов в системе лесной биоэкономики не достигает целей устойчивости развития, а меновая стоимость отстает от потребительской, то вполне обоснован вопрос корректировки налогово-бюджетных рычагов развития. Необходима не столько финансовая помощь государства, сколько технологическая платформа инновационного развития и грамотная финансовая дистрибуция средств, которая позволит улучшить условия управления различными локально-пространственными объектами, включая экосистемные услуги. При этом важна роль частного предпринимательства, государственно-частного партнерства и инвестирования, что в аспекте практической реализации лесных и лесоинженерных технологий ни в коем случае не должно сниматься со счетов.

Для лесного сектора Беларуси надежды на высокоэффективное биоэкономическое развитие связываются с адаптацией к глобальной рыночной экономике. Конкурентоспособность на уровне компаний напрямую зависит от диверсификации по продуктовым и услуговым направлениям использования ресурсов. Как показывает практика, процессы экономического развития на базе лесных территорий устремлены в стабилизацию работы промышленности, главным образом обрабатывающей, с выходом ее в стоимостном аспекте на повышательную траекторию. Для того, чтобы обеспечить благосостояние и занятость отраслей лесного хозяйства и лесной промышленности, следует рационально использовать ресурсы. В первую очередь, эта рационализация касается разработки и освоения тех продуктов, которые пользуются наибольшим спросом. Также следует понимать, что современный спрос и предложение - это очень динамичные понятия. Следует учитывать потребности будущего, заботясь о сохранении ресурсов и стимулировании экологической ответственности населения. В этом смысле мы узнали мнение опрашиваемых относительно:

1) существования предпочтений и перспектив по отдельным продуктовым направлениям;

2) социальных и культурных норм, которые представляют участники анкетирования в пользу различных лесных экосистем как объектов совместного потребления. 
Исходя из современных требований рынка, в состав самой перспективной продукции работники лесных отраслей включили строительные материалы, затем биотопливо и текстиль. Заметим, что технологии производства текстиля являются достаточно перспективными, и, по мнению исследователей [4], спрос активизируется в восточном регионе, где находятся наши основные стратегические партнеры. Инновационный продуктовый потенциал работники нелесных отраслей (в частности, в промышленности строительных материалов и химической промышленности) также определили в аспекте императивности строительных материалов, при этом обозначая важность производства химических веществ для продуктов и биотоплива, а также композиционных материалов. Таким образом, на основе социологического анализа нами была сформулирована «зонтичная» продуктовая конструкция. Во главе - общее направление, выделенное большинством респондентов как приоритетное, строительные материалы, куда входят многочисленные продуктовые объекты и позиции.

Однако комплексное направление инноватизации лесной биоэкономики «уходит» в сторону химической промышленности и преобразований биоресурсов в биоэнергию, основывается на уже имеющихся в стране разработках. Второе направление - лесохимия, бумажная и легкая промышленность, которые ориентируются на химические вещества и готовые продукты, композиционные материалы и текстить.

Выбор продуктовых стратегий развития это важнейший элемент в системе маркетинга. Он, безусловно, должен использоваться в системе поддержки принятия стратегических решений инновационного развития. Однако, как сказал Б. Зигмунт, «ценности не всегда выбираются сознательно» [5].

В работе зарубежных ученых [3] показана современная ситуация с развитием технологий химической промышленности и энергетики, что касается и производства биомассы. Как справедливо заявляют исследователи, новая парадигма социально-экономического развития стран предполагает «видение биомассы как заменителя нефти». Похожая ситуация и в Беларуси. Но исследователи предостерегают, что использование биомассы в качестве прямого заменителя нефти «не имеет большого экономического или экологического смысла» [6]. Все необходимо рассматривать в рамках меновой стоимости, цен. Авторы указанной работы выступают за термохимическое, химическое или биологическое преобразование биомассы в химические вещества и материалы, а не в топливо. С такими выводами стоит согласиться. Поэтому «зонтичная» конструкция строительных материалов (которая выстроена на основании опроса респондентов) должна быть откорректирована в пользу инноваций так называемого «переднего края» науки, а именно готовых химических продуктов, изготовленных на основе биомассы, так как при таком использовании имеются небольшие потери и выход продукции, измеряемый где-то в диапазоне $80 \%$. С учетом того, что в стране существует большой задел по химическим технологиям и уже построены биоперерабатывающие заводы, атомная станция, на фоне этого имеются значительные запасы воды, следует сосредоточить внимание на «водородной» экономике. В исследовании [6] показано, что именно водород будет играть важную роль в секторе чистой энергии, а не биомасса.

Белорусской практике требуется новая биоэкономика. Как показал наш опрос, ни один из респондентов не выделил гидрологическую функцию лесов в качестве одной из самых важных. Но в то же время общая функция «охрана природы» поставлена на первое место большинством опрашиваемых. С позиций широты охвата она может включать бизнес-процессные инновации, в том числе гидрологические.

Заключение. Проведенное исследование позволило определить контуры инновационного биоэкономического развития. И хотя, по мнению многих ученых, социологические опросы страдают от неучета различных социально-психологических факторов, от недостоверности имеющейся информации, настроений и даже от периода времени, в котором проводилось исследование $[7,8]$, следует заметить, что они так или иначе позволяют выстраивать структуру экономики, ее целевые функции. Что касается стратегического менеджмента и проектного финансирования лесной биоэкономики, то следует уделить внимание как настроениям аккумулирования средств из бюджетных источников, так и «пользовательскому» потенциалу. Важно понимать, что существенно улучшить условия инновационного развития лесной биоэкономики можно за счет разработки новых «прорывных» направлений продуктовой ориентации и монетизации нерыночных услуг лесов.

\section{Список литературы}

1. D'Amato D., Korhonen J. Integrating the Green Economy, Circular Economy and Bioeconomy in a Strategic Sustainability Framework // Ecol. Econ. 2021. No. 188. P. 107-143.

2. Chen Y., Chen C.-Y., Hsieh T. Exploration of Sustainable Development by Applying Green Economy Indicators // Environmental Monitoring Assessment. 2011. No. 182. P. 279-289. 
3. Kasztelan A. On the Road to a Green Economy: How Do European Union Countries 'Do Their Homework'? URL: https://www.researchgate.net/publication/354678163_On_the_Road_to_a_Green_Economy_ How_Do_European_Union_Countries_'Do_Their_Homework' (date of access: 15.09 .2021$)$.

4. Долженко И. Современные тенденции торговли текстильными товарами // Современный экономический успех. 2021. № 1. С. 119-125.

5. Зигмунд Б. Мыслить социологически. URL: https://www.litmir.me (дата обращения: 15.09.2021).

6. Yadav V. G., Yadav G. D., Patankar S. C. The production of fuels and chemicals in the new world: critical analysis of the choice between crude oil and biomass vis-à-vis sustainability and the environment. URL: https://doi.org/10.1007/s10098-020-01945-5 (date of access: 11.09.2021).

7. Хасс Дж. Социологический неоинституционализм и анализ организаций (предисловие к разделу) // Вестник Санкт-Петербургского университета. Экономика. 2007. № 3. С. 112-125.

8. Фомичева Т. В. Ценности россиян в период пандемии // Социальная политика и социология. 2021. № 1 (138). C. 178-185.

\section{References}

1. D'Amato D., Korhonen J. Integrating the Green Economy, Circular Economy and Bioeconomy in a Strategic Sustainability Framework. Ecol. Econ., 2021, no. 188, pp. 107-143.

2. Chen Y., Chen C.-Y., Hsieh T. Exploration of Sustainable Development by Applying Green Economy Indicators. Environmental Monitoring Assessment, 2011, no. 182, pp. 279-289.

3. Kasztelan A. On the Road to a Green Economy: How Do European Union Countries 'Do Their Homework'? Available at: https://www.researchgate.net/publication/354678163_On_the_Road_to_a_Green_ Economy_How_Do_European_Union_Countries_'Do_Their_Homework' (accessed 15.09.2021).

4. Dolzhenko I. Modern trends in textile trade. Sovremennyy ekonomicheskiy uspekh [Modern economic success], 2021, no. 1, pp. 119-125 (In Russian).

5. Zigmund B. Myslit' sotsiologicheski [To think sociologically]. Available at: https://www.litmir.me (accesed 15.09.2021).

6. Yadav V. G., Yadav G. D., Patankar S. C. The production of fuels and chemicals in the new world: critical analysis of the choice between crude oil and biomass vis-à-vis sustainability and the environmen. Available at: https://doi.org/10.1007/s10098-020-01945-5 (accessed 11.09.2021).

7. Hass Dzh. Sociological neoinstitutionalism and the analysis of organizations (preface to the section). Vestnik Sankt-Peterburgskogo universiteta. Ekonomika [Saint Petersburg University Journal of Economic Studies], 2007, no. 3, pp. 112-125 (In Russian).

8. Fomicheva T. V. The values of Russians in the pandemic. Sotsial'naya politika i sotsiologiya [Social policy and sociology], 2021, no. 1 (138), pp. 178-185 (In Russian).

\section{Информация об авторе}

Каштелян Таисия Васильевна - кандидат экономических наук, доцент, доцент кафедры организации производства и экономики недвижимости. Белорусский государственный технологический университет (220006, г. Минск, ул. Свердлова, 13а, Республика Беларусь). E-mail: taisiya_kascht@mail.ru

\section{Information about the author}

Kashtelyan Taisiya Vasil'yevna - PhD (Economics), Associate Professor, Assistant Professor, the Department of Production Organization and Real Estate Economics. Belarusian State Technological University (13a, Sverdlova str., 220006, Minsk, Republic of Belarus).E-mail: taisiya_kascht@mail.ru 